\title{
PERENCANAAN PERSEDIAAN SUKU CADANG (SPARE PART) MESIN TENUN SULZER RUTI BERDASARKAN ANALISIS KEANDALAN
}

\section{Teguh Baroto $^{1}$, Tutik Solikhati ${ }^{2}$}

\begin{abstract}
Availability of machine spare parts is very supporting for maintenance activity conducted in order to improve the machine performance. So far, PT. Eratex Djaja often have difficulty in arranging component stock particularly critical component of Sulzer Ruti machine, so it is necessary to determine the optimum stock condition to minimize resulted cost. In this research we will utilize probabilitical stock model with fixed amount of order ( $Q$ system model) in order to make average stock in storage as low as possible considering quite high price of the critical component. In addition to this, it is also required that level of component availability is maximized. Based on the stock model, we are able to approach the component amount required for a given period by assuming constant average defect rate. From the research can be conlused that the number of components must be required for quide tooth block assimetrical $=6$, upper mean brake lining blue $=10$, lower brake lining blue $=12$, and upper front brake lining blue $=15$.
\end{abstract}

\section{Key Words : Maintenance, Reliability, Stock.}

\section{PENDAHULUAN}

PT. Eratex Djaja, Ltd, Tbk Probolinggo merupakan perusahaan yang bergerak di bidang tekstil yang sebagian besar hasil produksinya yaitu sekitar $96 \%$ di ekspor keluar negeri, sedangkan sisanya dijual didalam negeri. Salah satu proses produksinya adalah proses weaving (proses tenun) yang sebagian besar menggunakan mesin tenun projectil merk Sulzer Ruti dengan tipe P7100 B 390 N1- I EPO 1 5120 buatan Swithzerland tahun 1994.

Proses produksi di PT. Eratex Djaja, Ltd, Tbk khususnya di departemen Weaving berlangsung secara terus menerus tanpa henti atau selama 24 jam sehari dan dengan kecepatan yang cukup tinggi yaitu $400 \mathrm{rpm}$. $\mathrm{Hal}$ ini menyebabkan komponen dari mesin tersebut harus diganti dengan yang baru, jika komponen tersebut mengalami kerusakan agar proses produksi dapat berjalan dengan lancar. Dari hasil pengamatan di lapangan, dalam sehari rata-rata terdapat $2-4$ komponen yang mengalami kerusakan dan harus diganti dengan yang baru.

Permasalahan yang timbul adalah banyaknya suku cadang yang disimpan di gudang dan dalam jangka waktu yang lama belum dimanfaatkan akibat dari pemesanan suku cadang yang terlalu besar. serta suku cadang harus diimport dari perusahaan pembuat mesin Sulzer Ruti yang berada di Switzerland dan waktu pemesanan sampai datangnya suku cadang rata-rata 3 bulan. Hal ini tentunya akan menimbulkan biaya yang besar untuk penyimpanan dan perawatan suku cadang di gudang.

Maka keandalan terhadap komponen kritis dari mesin Sulzer Ruti yaitu yaitu Guide Tooth Block Assimetrical Haf/Half $L=73 D_{1} D_{12}, 6 / 6$; Upper Rear Brake Lining 
Blue; Upper Front Brake Lining Blue dan Lower Brake Lining Blue serta jumlah suku cadang (komponen kritis) yang harus disediakan agar biaya yang ditimbulkan minimal dengan tingkat ketersediaan optimal.

\section{TINJAUAN PUSTAKA}

Keandalan didefinisikan dalam hal kinerja suatu sistem untuk memenuhi fungsi yang diharapkan, dan tidak ada perbedaan yang dibuat di lingkup kerusakan. Suatu sistem dikatakan rusak apabila ia berhenti memenuhi fungsi yang diinginkan. Apabila berhentinya suatu fungsi sistem seperti: mesin berhenti bekerja, peralatan komunikasi dalam sistem mati, maka sistem dalam keadaan benar-benar rusak.

Karena merupakan nilai probabilitas maka $\mathrm{R}$ bernilai $0 \leq \mathrm{R} \leq 1$.

$\mathrm{R}=1 \quad$ : Sistem dapat melakukan fungsinya dengan baik

$\mathrm{R}=0 \quad$ : Sistem tidak dapat melakukan tugas dengan baik

Karena keandalan juga ditentukan oleh waktu sebagai variabel random, maka diperlukan suatu fungsi keandalan. Dinotasikan :

$R(t)$ : berapa keandalan sistem jika dipakai selama t satuan waktu

$R(t) \quad$ : probabilitas sistem dapat berfungsi dengan baik selama pemakaian $[0, t]$

Sehingga :

$R(t) \quad=\mathrm{P}($ peralatan beroperasi $)$

$=P(X(t)=1)$

$$
\begin{aligned}
& =P(T>t) \\
& =1-P(T \leq t)=1-F(t)
\end{aligned}
$$

Dimana $F(t)$ merupakan fungsi distribusi kumulatif (Cumulative Distribution Function/CDF) umur (life time) sistem, atau fungsi distribusi kerusakan. Jika probabilitas fungsi kerapatan (Probability Density Function/PDF) merupakan turunan dari $F(t)$, maka :

$$
\begin{array}{lr}
f(t)=\frac{d F(t)}{d t} & f(t)=\frac{d(1-R(t))}{d t} \\
f(t)=-\frac{d R(t)}{d t} & R(t)=1-\int_{0}^{t} f(t) d t \\
\text { Sehingga : } & R(t)=\int_{t}^{\infty} f(t) d t
\end{array}
$$

\section{Model Sistem Persediaan Dengan Jumlah}

\section{Pemesanan Tetap (Q system)}

Notasi-notasi dan asumsi yang digunakan dalam model ini akan diuraikan sebagai berikut :

D =ekspektasi kebutuhan komponen/periode perencanaan

$\mathrm{Q}$ = besarnya jumlah komponen yang dipesan

$\mathrm{R}$ = besarnya titik pemesanan ulang (reorder point)

$\mathrm{T}=$ ekspektasi panjang siklus (bulan)

$\mathrm{L} \quad=$ lamanya selang waktu pemesanan komponen

$\mathrm{C}_{\mathrm{p}} \quad=$ besar ongkos pesan (Rp/pesanan)

$\mathrm{C}_{\mathrm{s}}=$ besar ongkos simpan (Rp/unit/periode)

$\mathrm{C}_{\mathrm{k}}=$ ongkos hilangnya kesempatan memperoleh keuntungan (Rp/unit)

Distribusi kemungkinan kebutuhan komponen selama waktu pemesanan adalah 
diskrit dengan distribusi kemungkinan $\mathrm{P}(\mathrm{x})$ dan rata-rata $\mu$. Apabila kebutuhan komponen selama waktu pemesanan adalah $\mathrm{x}$, maka pada saat sebelum pemesanan komponen tiba akan terjadi kekurangan persediaan sebesar :

$$
\eta(x, r)=\left\{\begin{array}{l}
0, j i k a . x<r \\
x-r, \text { jika } x \geq r
\end{array}\right\}
$$

Ekspektasi kekurangan persediaan sebelum pemesanan tiba/siklus adalah :

$$
\eta(x, r)=\sum_{x=r+1}^{\infty}(x-r) \cdot P(x)
$$

Karena dalam kasus "lost sales" tidak diperkenankan adanya kekurangan persediaan, maka ekspektasi jumlah kebutuhan komponen selama satu siklus adalah $=\frac{Q \eta(x, r)}{d}$

Ekspektasi panjang siklus $\mathrm{T}$ adalah $=$

$$
\frac{\mathrm{Q}+\eta(\mathrm{x}, \mathrm{r})}{\mathrm{d}}
$$

1. Ongkos total pemesanan komponen ratarata/periode adalah :

$$
\begin{aligned}
\mathrm{OP} & =\frac{C_{p}}{T} \\
& =\frac{C_{P} \cdot d}{Q+\eta(x, r)}
\end{aligned}
$$

Pada saat sebelum datangnya pemesanan komponen, sisa persediaan (kasus lost sales) adalah :

$$
\varepsilon(x, r)=\left\{\begin{array}{l}
r-x, j i k a . r \geq x \\
0, j i k a . r<x
\end{array}\right\}
$$

Ekspektasi sisa persediaan sebelum datangnya pemesanan adalah :

$\mathrm{S}=\mathrm{r}-\mu+\eta(\mathrm{x}, \mathrm{r})$

Ekspektasi persediaan setelah datangnya pemesanan komponen adalah :

$$
\begin{aligned}
\mathrm{M} & =\mathrm{Q}+\mathrm{S} \\
& =\mathrm{Q}+\mathrm{r}-\mu+\eta(\mathrm{x}, \mathrm{r})
\end{aligned}
$$

2. Ongkos total penyimpanan komponen rata-rata/periode adalah :

$$
\begin{aligned}
& \text { OS }= \\
& \mathrm{C}_{\mathrm{S}} / 2[\mathrm{Q}+2 \mathrm{r}-\mu+\eta(\mathrm{x}, \mathrm{r})]+\frac{\mu \mathrm{C}_{\mathrm{S}}}{2[\mathrm{Q}+\eta(\mathrm{x}, \mathrm{r})]}+ \\
& {\left[\sum_{\mathrm{x}=\mathrm{x}+1}^{\infty} \frac{(\mathrm{x}-\mathrm{r})^{2}+\mathrm{xr}}{\mathrm{x}} \cdot \mathrm{P}(\mathrm{x})-[\mathrm{Q}+\eta(\mathrm{x}, \mathrm{r})]\right]}
\end{aligned}
$$

Ekspektasi kebutuhan komponen yang tidak dapat dipenuhi (demand lost) 1 siklus adalah :

$$
\eta(x, r)=\sum_{x=r+1}^{\infty}(x-r) \cdot P(x)
$$

3. Ongkos total kekurangan persediaan komponen rata-rata/periode adalah :

$$
\begin{aligned}
& \mathrm{OK}=\left(\frac{\mathrm{C}_{\mathrm{K}}}{\mathrm{T}}\right) \eta(\mathrm{x}, \mathrm{r}) \\
& \mathrm{OK}=\mathrm{C}_{\mathrm{K}}\left(\frac{\mathrm{d}}{\mathrm{Q}+\eta(\mathrm{x}, \mathrm{r})}\right) \eta(\mathrm{x}, \mathrm{r})
\end{aligned}
$$

Jadi ongkos total sistem persediaan komponen rata-rata/periode adalah :

$$
\mathrm{OT}(\mathrm{Q}, \mathrm{r})=\mathrm{OP}+\mathrm{OS}+\mathrm{OK}
$$

4. Besarnya ketersediaan komponen ditentukan berdasarkan pada ekspektasi kekurangan persediaannya, yaitu :

$$
\begin{aligned}
\mathrm{TK}=1-\frac{\eta(\mathrm{x}, \mathrm{r})}{\mathrm{Q}+\eta(\mathrm{x}, \mathrm{r})} \\
\mathrm{TK}=1-\frac{\eta(\mathrm{x}, \mathrm{r})}{\mathrm{Q}+\sum_{\mathrm{x}=\mathrm{r}+1}^{\infty}(\mathrm{x}-\mathrm{r}) \cdot \mathrm{P}(\mathrm{x})}
\end{aligned}
$$

\section{METODOLOGI PENELITIAN}

Data yang diperlukan adalah data waktu antar kerusakan komponen kritis yang diperoleh dari pencatatan dokumen perusahaan, baik pada bagian maintenance 
maupun pada bagian gudang spare part mesin tenun Sulzer Ruti.

\section{Tahapan Pengolahan Data}

Proses pengolahan data meliputi beberapa tahapan, yaitu :

1. Uji kecocokan distribusi waktu antar kerusakan komponen kritis dengan menggunakan uji Kolmogorov Smirnov dan perhitungan parameter-parameter keandalan dari komponen tersebut.

2. Perhitungan fungsi keandalan dan laju kerusakan komponen kritis.

3. Perhitungan ekspektasi jumlah kebutuhan suku cadang (komponen kritis).

4. Penentuan $\mathrm{Q}$ dan $\mathrm{r}$ yang meminimalkan total biaya persediaan

\section{HASIL DAN PEMBAHASAN}

Berdasarkan hasil pengujian statistik terhadap waktu antar kerusakan komponen dengan menggunakan uji Kolmogorov Smirnov dapat dilihat pada tabel 1 .

Tabel 1

Distribusi Komponen Kritis Dan Parameternya

\begin{tabular}{|c|l|c|c|}
\hline No & \multicolumn{1}{|c|}{$\begin{array}{c}\text { Nama } \\
\text { Komponen }\end{array}$} & Distribusi & Parameter \\
\hline 1 & $\begin{array}{l}\text { Guide Tooth } \\
\text { Block } \\
\text { Assimetrical } \\
\text { Half/Half }\end{array}$ & Normal & $\mu=139,014$ \\
\hline 2 & $\begin{array}{l}\text { Upper Rear } \\
\text { Brake Lining } \\
\text { Blue }\end{array}$ & Normal & $\mu=149,167$ \\
\hline
\end{tabular}

\begin{tabular}{|c|c|c|c|}
\hline No & $\begin{array}{c}\text { Nama } \\
\text { Komponen }\end{array}$ & Distribusi & Parameter \\
\hline 3 & $\begin{array}{l}\text { Lower Brake } \\
\text { Lining Blue }\end{array}$ & $\begin{array}{c}\text { Lognorm } \\
\text { al }\end{array}$ & $\mu=135,452$ \\
\hline 4 & $\begin{array}{l}\text { Upper Front } \\
\text { Brake lining } \\
\text { Blue }\end{array}$ & Lognorm & $\mu=131,448$ \\
\hline
\end{tabular}

Selanjutnya dari hasil perhitungan dengan menggunakan paket program Mathcad fungsi keandalan, laju kerusakan dan ekpektasi masa pakai (MTTF) untuk setiap komponen dengan periode perencanaan 4 bulan atau 120 hari adalah sebagai berikut

1). Komponen Guide Tooth Block Assimetrical Half

a. Fungsi keandalannya adalah :

$$
\begin{aligned}
& R(t)=\int_{t}^{\infty} \frac{1}{\sigma \sqrt{2 \pi}} e^{\left[\frac{(t-\mu)^{2}}{2 \sigma^{2}}\right]} d t \\
& R(t)=0.626
\end{aligned}
$$

b. Fungsi laju kerusakannya adalah :

$$
\lambda(t)=\frac{\frac{1}{\sigma \sqrt{2 \pi}} e^{\left[\frac{(t-\mu)^{2}}{2 \sigma^{2}}\right]}}{R(t)}
$$$$
\lambda(t)=0.01
$$

c. Mean Time To Failure (MTTF) adalah :

$$
\begin{aligned}
& \text { MTTF }=\mu \\
& M T T F=139.014 \text { hari. }
\end{aligned}
$$

2). Komponen Upper Rear Brake Lining Blue

a. Fungsi keandalannya adalah :

$$
\begin{aligned}
& R(t)=\int_{t}^{\infty} \frac{1}{\sigma \sqrt{2 \pi}} e^{\left[-\frac{(t-\mu)^{2}}{2 \sigma^{2}}\right]} d t \\
& R(t)=0.846
\end{aligned}
$$


b. Fungsi laju kerusakannya adalah

$$
\begin{aligned}
& \lambda(t)=\frac{\frac{1}{\sigma \sqrt{2 \pi}} e^{\left[-\frac{(t-\mu)^{2}}{2 \sigma^{2}}\right]}}{R(t)} \\
& \lambda(t)=9,804 \cdot 10^{-3}
\end{aligned}
$$

c. Mean Time To Failure (MTTF) adalah :

$$
\begin{aligned}
& \text { MTTF }=\mu \\
& \text { MTTF }=149,167 \text { hari. }
\end{aligned}
$$

3). Komponen Lower Brake Lining Blue

a. Fungsi keandalannya adalah :

$$
\begin{aligned}
& R(t)=1-\int_{0}^{t} \frac{1}{\sigma \sqrt{2 \pi}} e^{\left[-\frac{(\ln (t)-\mu t)^{2}}{2 \sigma^{2}}\right]} d t \\
& R(t)=0,733
\end{aligned}
$$

b. Fungsi laju kerusakannya adalah :

$$
\lambda(t)=\frac{\frac{1}{\sigma \sqrt{2 \pi}} e^{\left[-\frac{(\ln (t)-\mu t)^{2}}{2 \sigma t^{2}}\right]}}{R(t)}
$$

$$
\lambda(t)=0.016
$$

c. Mean Time To Failure (MTTF) adalah :

$$
\begin{aligned}
& \text { MTTF }=\mu \\
& \text { MTTF }=135.452 \text { hari. }
\end{aligned}
$$

4). Komponen Upper Front Brake Lining Blue

a. Fungsi keandalannya adalah :

$$
\begin{aligned}
& R(t)=1-\int_{0}^{t} \frac{1}{\sigma \sqrt{2 \pi}} e^{\left[-\frac{(\ln (t)-\mu)^{2}}{2 \sigma^{2}}\right]} d t \\
& R(t)=0.715
\end{aligned}
$$

b. Fungsi laju kerusakannya adalah :

$$
\lambda(t)=\frac{\frac{1}{\sigma \sqrt{2 \pi}} e^{\left[-\frac{(\ln (t)-\mu t)^{2}}{2 \sigma t^{2}}\right]}}{R(t)}
$$

$$
\lambda(t)=0.018
$$

c. Mean Time To Failure (MTTF) adalah :

$$
\begin{aligned}
& \text { MTTF }=\mu \\
& M T T F=131,448 \text { hari. }
\end{aligned}
$$

Dari hasil perhitungan tersebut dapat diketahui bahwa dengan periode perencanaan 4 bulan atau 120 hari, komponen yang memiliki nilai keandalan paling besar adalah komponen Upper Rear Brake Lining Blue yaitu sebesar 0,846. Dengan nilai keandalan yang sangat besar, maka sebaliknya nilai laju kerusakannya menjadi paling kecil yaitu $9,804 \times 10^{-3}$. Hal ini terjadi karena komponen ini memiliki ekspektasi masa pakai atau mean time to failure (MTTF) sebesar 149,167, sehingga komponen ini akan mengalami kerusakan dan diganti dengan yang baru setelah selang waktu 149,167 hari.

Sedangkan komponen yang memiliki nilai keandalan yang paling kecil dengan periode perencanaan 120 hari adalah komponen Guide Tooth Block Assimetrical Half/Half yaitu sebesar 0,626 dengan nilai laju kerusakan sebesar 0,01 . Komponen ini memiliki ekspektasi masa pakai (MTTF) yang mendekati periode perencanaannya, yaitu sebesar 139,014 hari, sehingga keandalannya menjadi paling kecil diantara ketiga komponen kritis lainnya

Dengan menggunakan bantuan software Excell, maka didapatkan keputusan mengenai kondisi persediaan yang optimal adalah pasangan harga $Q$ dan $r$ yang 
meminimalkan total ongkos persediaan dengan tingkat ketersediaan yang optimal.Batas minimal tingkat ketersediaan yang ditetapkan oleh perusahaan adalah sebesar $95 \%$.

Hasil iterasi perhitungan tersebut dapat dilihat pada tabel di bawah ini :

Tabel 2

Variabel Keputusan Persediaan Untuk Setiap Komponen

\begin{tabular}{|c|c|c|c|c|c|c|}
\hline $\begin{array}{l}N \\
0\end{array}$ & $\begin{array}{c}\text { Nama } \\
\text { Kompone } \\
n\end{array}$ & $\mathbf{R}$ & $\mathbf{Q}$ & $S$ & OT (Rp) & $\begin{array}{l}\text { TK } \\
(\%)\end{array}$ \\
\hline 1 & $\begin{array}{l}\text { Guide } \\
\text { Tooth } \\
\text { Block } \\
\text { Assimet } \\
\text { rical } \\
\text { Half/Hal } \\
\text { f } \\
\end{array}$ & $\begin{array}{l}13 \\
14 \\
15 \\
16 \\
17\end{array}$ & $\begin{array}{c}10 \\
8 \\
6 \\
5 \\
5\end{array}$ & $\begin{array}{l}6 \\
7 \\
8 \\
9\end{array}$ & $\begin{array}{c}829130,7 \\
76.367,5 \\
746067,5 \\
760193,9 \\
793801,4\end{array}$ & $\begin{array}{l}99,3 \\
99,6 \\
99,7 \\
99,8 \\
99,9\end{array}$ \\
\hline 2 & $\begin{array}{l}\text { Upper } \\
\text { Rear } \\
\text { Brake } \\
\text { Lining } \\
\text { Blue } \\
\end{array}$ & $\begin{array}{c}6 \\
7 \\
8 \\
9 \\
10\end{array}$ & $\begin{array}{c}16 \\
12 \\
10 \\
10 \\
9\end{array}$ & $\begin{array}{l}3 \\
4 \\
5 \\
6 \\
7\end{array}$ & $\begin{array}{l}100450,8 \\
85115,86 \\
81255,93 \\
83353,58 \\
87699,28\end{array}$ & $\begin{array}{l}99,6 \\
99,8 \\
99,9 \\
99,9 \\
99,9\end{array}$ \\
\hline 3 & $\begin{array}{l}\text { Lower } \\
\text { Brake } \\
\text { Lining } \\
\text { Blue }\end{array}$ & $\begin{array}{c}9 \\
10 \\
11 \\
12 \\
13\end{array}$ & $\begin{array}{l}18 \\
14 \\
12 \\
11 \\
10\end{array}$ & $\begin{array}{l}4 \\
5 \\
6 \\
7 \\
8\end{array}$ & $\begin{array}{l}146.704,2 \\
127.087,4 \\
119.850,1 \\
120.280,9 \\
124.577,9\end{array}$ & $\begin{array}{l}99,7 \\
99,8 \\
99,9 \\
99,9 \\
99,9\end{array}$ \\
\hline 4 & $\begin{array}{l}\text { Upper } \\
\text { Front } \\
\text { Brake } \\
\text { Lining } \\
\text { Blue }\end{array}$ & $\begin{array}{l}11 \\
12 \\
13 \\
14 \\
15\end{array}$ & $\begin{array}{l}20 \\
17 \\
15 \\
14 \\
14\end{array}$ & $\begin{array}{l}5 \\
6 \\
7 \\
8\end{array}$ & $\begin{array}{c}130.284,8 \\
116.848 \\
112.383,9 \\
113.208,7 \\
116.655,3\end{array}$ & $\begin{array}{l}99,8 \\
99,9 \\
99,9 \\
99,9 \\
99,9\end{array}$ \\
\hline
\end{tabular}

Berdasarkan hasil diatas maka, maka kondisi persediaan yang paling optimal diantara beberapa iterasi perhitungan total ongkos persediaan dari setiap komponen kritis, ditunjukkan dalam bentuk tabel seperti di bawah ini :
Tabel 3

Kondisi Persediaan Optimal Setiap Komponen

\begin{tabular}{|c|l|c|c|c|c|c|}
\hline $\begin{array}{c}\text { N } \\
\mathbf{0}\end{array}$ & \multicolumn{1}{|c|}{$\begin{array}{c}\text { Nama } \\
\text { Komponen }\end{array}$} & R & Q & S & OT(Rp) & $\begin{array}{c}\text { TK(\% } \\
\text { 1 }\end{array}$ \\
\hline $\begin{array}{l}\text { Guide Tooth } \\
\text { Block } \\
\text { Assimetrical } \\
\text { half/I Ialf }\end{array}$ & 15 & 6 & 7 & $\begin{array}{l}746.067, \\
5\end{array}$ & 99.7 \\
\hline 2 & $\begin{array}{l}\text { Upper Rear } \\
\text { Brake Lining } \\
\text { Blue }\end{array}$ & 8 & 10 & 5 & 81255.93 & 99.9 \\
\hline 3 & $\begin{array}{l}\text { Lower Brake } \\
\text { Lining Blue }\end{array}$ & 11 & 12 & 6 & $\begin{array}{l}119.850, \\
1\end{array}$ & 99.9 \\
\hline 4 & $\begin{array}{l}\text { Upper Front } \\
\text { Brake Lining } \\
\text { Blue }\end{array}$ & 13 & 15 & 7 & $\begin{array}{l}112.383, \\
9\end{array}$ & 99.9 \\
\hline
\end{tabular}

Dari tabel di atas dapat diketahui bahwa :

1. Komponen Guide Tooth Block Assimetrical Half/Half

Jumlah komponen yang dipesan sebesar 6 komponen untuk setiap kali pesan, dengan tingkat persediaan komponen untuk jangka waktu 120 hari atau 4 bulan adalah 21 komponen. Pemesanan dilakukan jika komponen yang ada di gudang sudah mencapai titik pemesanan kembali atau reorder point (r) yang berjumlah 15 komponen. Sedangkan untuk menghadapi fluktuasi kerusakan atau kebutuhan komponen selama lead time, digunakan sediaan pengaman atau safety stock sebesar 7 komponen. Dengan kebijaksanaan persediaan seperti ini, total biaya persediaan menjadi minimal yaitu sebesar Rp. 746.067,5 dengan tingkat ketersediaan (TK) $99,76 \%$.

2. Komponen Upper Rear Brake Lining Blue

Jumla komponen yang dipesan adalah sebesar 10 komponen untuk setiap kali 
pesan, dengan tingkat persediaan komponen untuk jangka waktu 120 hari atau 4 bulan adalah 18 komponen. Pemesanan dilakukan jika komponen yang ada di gudang sudah mencapai titik pemesanan kembali atau reorder point (r) yang berjumlah 8 komponen. Sedangkan untuk menghadapi fluktuasi kerusakan atau kebutuhan komponen selama lead time, digunakan sediaan pengaman atau safety stock sebesar 5 komponen. Dengan kebijaksanaan persediaan seperti ini, total biaya persediaan menjadi minimal yaitu sebesar Rp. 81.255,93 dengan tingkat ketersediaan (TK) 99,95\%.

3. Komponen Lower Brake Lining Blue Jumlah komponen yang dipesan sebesar 12 komponen untuk setiap kali pesan, dengan tingkat persediaan komponen untuk jangka waktu 120 hari atau 4 bulan adalah 23 komponen. Pemesanan dilakukan jika komponen yang ada di gudang sudah mencapai titik pemesanan kembali atau reorder point (r) yang berjumlah 11 komponen. Sedangkan untuk menghadapi fluktuasi kerusakan atau kebutuhan komponen selama lead time, digunakan sediaan pengaman atau safety stock sebesar 6 komponen. Dengan kebijaksanaan persediaan seperti ini, total biaya persediaan menjadi minimal yaitu sebesar Rp. $119.850,1$ dengan tingkat ketersediaan (TK) $99,93 \%$.

4. Komponen Upper Front Brake Lining Blue
Jumlah komponen yang dipesan sebesar 15 komponen untuk setiap kali pesan, dengan tingkat persediaan komponen untuk jangka waktu 120 hari, atau 4 bulan adalah 28 komponen. Pemesanan dilakukan jika komponen yang ada di gudang sudah mencapai titik pemesanan kembali atau reorder point (r) yang berjumlah 13 komponen. Sedangkan untuk menghadapi fluktuasi kerusakan atau kebutuhan komponen selama lead time, digunakan sediaan pengaman atau safety stock sebesar 7 komponen. Dengan kebijaksanaan persediaan seperti ini, total biaya persediaan menjadi minimal yaitu sebesar Rp. $112.383,9$ dengan tingkat ketersediaan (TK) $99,96 \%$.

\section{KESIMPULAN}

1. Dari hasil pengujian dan perhitungan parameter keandalan, nilai keandalan, laju kerusakan dan rata-rata waktu antar kerusakan (MTTF) untuk keempat komponen kritis, yaitu :

a. Untuk komponen Guide Tooth Block Assimetrical Half/Half :

i. Nilai Keandalan $R(t)=0,626$

ii. Laju Kerusakan $\lambda(t)=0,01$

iii. $\mathrm{MTTF}=139,014$ hari

b. Untuk komponen Upper Rear Brake Lining Blue :

i. Nilai Keandalan $R(t)=0,846$

ii. Laju Kerusakan $\lambda(t)=9,804 \times$ $10^{-3}$

iii. $\mathrm{MTTF}=149,167$ hari 
c. Untuk komponen Lower Brake Lining Blue

i. Nilai Keandalan $R(t)=0,733$

ii. Laju Kerusakan $\lambda(t)=0,016$

iii. $\mathrm{MTTF}=135,452$ hari

d. Untuk komponen Upper Front Brake Lining Blue :

i. Nilai Keandalan $R(t)=0,715$

ii. Laju Kerusakan $\lambda(t)=0,018$

iii. $\mathrm{MTTF}=131,448$ hari

2. Hasil perhitungan model sistem persediaan dengan ongkos total minimal untuk masing-masing komponen dapat dilihat sebagai berikut :

a. Komponen Guide Tooth Block Assimetrical Half/Half: Jumlah komponen yang dipesan $(\mathrm{Q})=6$, reorder point $(\mathrm{r})=15$, persediaan pengaman atau safety stock $(\mathrm{s})=7$

b. Komponen Upper Rear Brake Lining Blue: Jumlah komponen yang dipesan $(\mathrm{Q})=10$, reorder point $(\mathrm{r})=8$, persediaan pengaman atau safety stock $(\mathrm{s})=5$

c. Komponen Lower Brake Lining Blue : Jumlah komponen yang dipesan $(\mathrm{Q})=12$, reorder point $(\mathrm{r})$ $=11$, persediaan pengaman atau safety stock $(\mathrm{s})=6$

d. Komponen Upper Front Brake Lining Blue : Jumlah komponen yang dipesan $(\mathbf{Q})=15$, reorder point $(\mathrm{r}) \quad=13$, persediaan pengaman atau safety stock $(\mathrm{s})=7$

\section{DAFTAR PUSTAKA}

Alkaf, Abdullah 1992, Teknik Keandalan

Sistem., Jurusan teknik Elektro, FTI ITS, Surabaya,

Biegel, John E 1992., Pengendalian Produksi : Suatu Pendekatan

Kuantitatif, Akademika Pressindo, Jakarta,

Fortuin, Leonard,1984, Expected Demand For Service Part When Failure Have A Weibull Distribution, European Journal Of Operation Research

Lewis, E.E., 1987. Introduction To Reliability Engineering, John Wiley \& Sons, Canada.

Leemis, Lawrence M., 1995, Reliability : Probabilistic Models And Statistical Methods, Prentice Hall, New Jersey.

Rammakumar, R., 1993, Engineering Reliability : Fundamentals And Aplication, Prentice Hall, New Jersey.. Siregar, Aprillian, 1996, Pengembangan Model Persediaan Komponen Suku cadang Berdasarkan Keandalan (Studi Kasus Pada PT. United Tractors), Tesis, ITS.

Starr, Martin K., dan Miller, David W.1981, Inventory Control : Theory And Practice, Prentice Hall, New York.

Tarsine, Richard J., 1994, Principles of Inventory And Material Management, Fourth Edition, Prentice Hall International Inc., New Jersey. 